\title{
Research on the Application of Xihaigu's Folk Art in Local Art Teaching in Colleges and Universities
}

\author{
Xueyan Ma \\ Ningxia Normal University, Art school, China, 756099
}

Keywords: Xihaigu, Folk Art, Teaching, Application

\begin{abstract}
The Xihaigu folk art is the crystallization of the collective wisdom of the people of the Xihaigu labor, and the application of Xihaigujia folk art resources to the art teaching of local colleges and universities can stimulate students' love of national art and promote the inheritance of folk art And development. This article on how to Xihaigu folk art infiltration to the local college art teaching research, so that students can more in-depth understanding of the traditional culture of the West Hugu area for contemporary college students to improve the quality of traditional culture and national pride to provide a reference Information, with a view to promoting the West to promote the development of folk art.
\end{abstract}

\section{Introduction}

With the progress of society, the improvement of people's living standard, and the acceleration of urbanization process, the folk art, which was closely connected with the life, production, customs and other customs of the working people, was also affected by different levels. Although, in recent years, the state has introduced a lot of relevant policy incentives to support the relevant agencies to protect and inherit folk art, but because some folk art is the old man, folk art depends on the survival of the natural environment has changed, Art work is less and less, folk art gradually marginalized. As a university teacher, we have the duty to pay attention to the realization of the cultural tradition of the nation itself in the art education of the university, to study and find a teaching method which conforms to this artistic value culture system. "Folk art should be included in a greater proportion University art teaching classroom, into our university art education, so that students with the existing knowledge and experience, active and active access to the Chinese folk art re-understanding and basic beliefs of national culture. "Mr. Lu Xun Said: the more the nation is the world, "folk art is the basis of all art, whether it is the history of the court art, literati doctor art, religious art, or modern art creation, their development are inseparable. Therefore, we should be extremely limited to the Xihaigu folk art into the local college art teaching, in order to expand the thinking of college students, to stimulate their inspiration, open their artistic vision.

\section{The Xihaigu and the Xihaigu Folk Art}

The hilly area of the Loess Plateau hilly area in the southern part of Ningxia is characterized by poor weather conditions and poor natural conditions. It is a combination of nomadic culture and farming culture. The characteristics of agricultural civilization and the characteristics of nomadic civilization are all on this land leaving a deep imprint, there have been as a military juncture to the border, it is the ancient Silk Road must pass through. Although the geographical location of the Xihaigu area is relatively narrow, the social environment has long been in a closed state, but with the exchange of other cultures has never been interrupted, has been in a variety of cultural and ideological collision with each other in the state. Xihaigu area is Ningxia Hui relatively concentrated areas, so the rich national characteristics are to add this piece of land to the charm of many bright colors. Xihaigu folk art is in this soil growth and development.

Folk art is the working people in the world, the transformation of the world in the course of practice, in their own unique way in different places, different ethnic groups are produced in the 
Chinese culture is an important part. "A lot of folk art works are inseparable from the practicality of this fundamental" the same, the Xihaigu folk art is to meet the Xihaigu land on the people's basic necessities, customs and other needs exist, simple and natural, always maintained the most primitive state of human culture and art. As the Xihaigu this place has been the Central Plains culture, nomadic culture, Silk Road culture, Islamic culture and other cultural impact, deep accumulation of history and culture, folk art resources are more abundant. Xihaigu folk art exposure to the Xihaigu this piece of barren land and here the folk culture is closely linked, such as weddings and funerals in the folk art, festivals in the folk art, modeling ancient humble, rich colors. Due to geographical constraints and economic backwardness and other reasons, the Xihaigu folk art has an independent personality and unique appearance, desolate and vigorous. Here the rich folk art style, contains the Xihaigu this piece of land people's good wishes, record the Xihaigu heart of the course, reflecting the unique beauty of the Xihaigu.

\section{The Importance of Applying Xihaigu Folk Art to Local College Art Teaching}

Excellent folk art is a nation of civilization and the crystallization of the crystallization of wisdom, is the world's cultural diversity of important resources, it is one of the art treasures of all mankind, for the modern society and human beings have provided irreplaceable spiritual nutrients, but also for other art provides a wide range of reference and inspiration. But with the continuous improvement of the material and cultural needs of the people, in the face of the impact and challenges of the modern market economy, how to make our excellent traditional art to a more distant future, how to effectively inherit the Xihaigu and folk art, and its protection development is the primary problem.

Colleges and Universities Have the Ability to Study, Protect and Inherit Folk Art. The local colleges and universities have the ability to study, inherit and develop folk art, have the advantage of relying on the local folk culture, the university is the base of cultivating fine arts professionals, the introduction of Xihaigu folk art into the art teaching of local colleges and universities to a certain extent can be resolved. It is necessary to construct more regional folk art teaching ideas in the protection and research of Xihaigu folk art in order to let more students participate in the crises faced by modern folk art in the modern society. Whether it is from the carry forward the Xihaigu folk art itself or from improving the overall quality of students, as a local university, are duty-bound, but also an effective way to serve the university.

The Xihaigu Folk Art is the Useful Supplement for Local College Art Teaching. There is no awareness, protection and inheritance cannot talk about, in the local colleges and universities to establish a folk art teaching system is a good complement and improvement of art education greatly enriched the art content of colleges and universities, but also an important way of regional cultural construction. So that students understand and master the knowledge and skills of Xihaigu folk art, enhance students' recognition of outstanding national culture is very important to carry forward the traditional culture of the region, for the development of modern art has an important reference value and help, the earth inspired students' artistic creation.

The Training of Xihaigu Folk Art Successor. In addition to the study of art professional knowledge, the local colleges and universities should not only spread the folk culture of the Xihaigu, but also should study and study the cultural knowledge of the West and the Qinghai folk culture, and integrate the folk art resources of the Xihaigu, and apply it appropriately and optimize the art teaching. Through the opening of the Xihaigu folk art courses, so that contemporary college students are interested in learning folk art, and in the traditional folk culture to learn to understand and reflect on to enhance the aesthetic realm, so that students can be based on the original innovation, the development of folk art. 


\section{The Application Strategy of Xihaigu Folk Art in Arts Teaching}

Create a New Teaching Model and Improve the Teaching Effect of the Xihaigu Folk Art. The use of scientific management methods of the university systematically collect the Xihaigu folk art resources to be analyzed and carried out research, the Xihaigu folk art as a course in the local colleges and universities to carry out the spread, and art and other related courses of mutual penetration, combined with the teaching, breaking a single classroom teaching model, rich way of transmission, through multi-channel and multi-way communication and learning, so that students in different places, through different forms of learning to understand the essence of Xihaigu folk art, Solid folk art to explore the interest, to deepen their students in their own region of the customs and folk culture of love, to stimulate students' creative inspiration.

The Preparation of Xihaigu Folk Art Teaching Materials Teaching. Local colleges and universities can be based on their own characteristics and geographical characteristics, contact the Xihaigu folk art heritage, as well as the school fine arts professional teachers set up a group to promote the Xihaigu folk art as the leading, select the local characteristics of rich, easy to carry out folk art style, Xihaigu folk art teaching materials. And to develop a complete teaching plan, the region's folk art resources to organize a systematic arrangement.

Establish the Xihaigu Folk Art Gallery. The establishment of the school "Xihaigu folk art exhibition hall", will distinctive distinctive folk art forms such as paper cutting, embroidery, clay sculpture and peasant painting display, so that students can be close to folk art, can more intuitive to see the appearance of folk art color, so that students through these works perceived in these works in the cultural connotation, to enhance students of the Xihaigu folk art close feeling. As Jin Zhilin said: "Chinese folk art is the most extensive mass of Chinese national art, the most closely related with the social life, the most rich historical and cultural connotation, the most extensive geographical features, the most distinctive ethnic characteristics of the well-known cultural form ...... is a national history and culture of the living fossils and museums. "So, it is necessary for us to Xihaigu folk art works set up museums or museums together.

Open the Xihaigu Folk Art Study Class. The establishment of the Xihaigu folk art school inspection classes and organize students to visit the local folk art of the descendants of the folk art of the base or folk art workshop, immersive feelings of the original state of folk art. Through field investigation, students interviewed the inheritors to understand the occurrence, development and personnel turnover of such folk art. In addition to the collection, recording, video recording, in-depth understanding of local history and culture, traditional customs, folk art, etc., in order to maximize the use of folk art resources, broaden the students' artistic vision, lead the students approached the people, understand the Xihaigu folk art, from the whole rich art professional curriculum training system, and ultimately promote the local traditional culture heritage.

Establish the Xihaigu Folk Art Hall. The establishment of the "Xihaigu folk art lectures", invited some of the Xihaigu folk art inheritors into the classroom, they have a very skilled folk art creative ability, we cannot ignore the outstanding teachers outside the school. So that these inheritors and students face to face communication, through the introduction of these inheritors, so that students of the Xihaigu folk art of humanistic value have a more in-depth understanding and understanding, enhance students to learn the Xihaigu folk art interest and enthusiasm. For example, folk paper-cut, we all know, paper-cut art of the draft, scissors, engraved method is dynamic, so that the origins of paper-cut art in the classroom to demonstrate, so more intuitive, more exciting students enthusiasm. The establishment of the Xihaigu folk art lectures, for the Xihaigu-based folk art heritage and development of a steady stream of new forces.

\section{The Significance of Setting up Folk Art Classes in Local Colleges and Universities}

Colleges and universities are important channels for the inheritance and development of traditional Chinese culture. Should let the students a full range of understanding of the local folk art, in the inheritance of outstanding folk traditional culture at the same time, should keep pace with the times, pay attention to innovation, so as to better carry forward the traditional culture, Vitality, 
which is the local colleges and universities in practice continue to explore and pursue.

\section{Acknowledgements}

Fund Project: This paper is 2017 Ningxia Normal College "Western first-class" subject education subject special research project key project fund grant, project number: YLXKZD1744

\section{References}

[1] Liu Shijun. Chinese folk art Chengdu [M], Chengdu: Southwest Jiaotong University Press, 2010.5

[2] Xu Qingqing. Folk Art [M], Beijing: China Textile Publishing House, 2012.4

[3] Jin Zhilin. Chinese folk art [M] Beijing: Wuzhou Communication Publishing House, 2010.1

[4] Tiger West Hill. Xihaigu folk paper-cut (Volume III) [M], Yinchuan: Sunshine Publishing House, 2015.12 